\title{
Quantitative magnetic resonance image analysis of the cerebellum in macrocephalic and normocephalic children and adults with autism
}

\author{
HOWARD B. CLEAVINGER, ${ }^{1}$ ERIN D. BIGLER, ${ }^{1,2,4}$ JAMIE L. JOHNSON,${ }^{1}$ JEFFREY LU, ${ }^{3}$ \\ WILLIAM McMAHON, ${ }^{2,4}$ AND JANET E. LAINHART ${ }^{2,4}$ \\ ${ }^{1}$ Departments of Psychology and Neuroscience, Brigham Young University, Provo, Utah \\ ${ }^{2}$ Department of Psychiatry, University of Utah, Salt Lake City, Utah \\ ${ }^{3}$ Department of Anesthesiology, University of Utah School of Medicine, Salt Lake City, Utah \\ ${ }^{4}$ The Brain Institute of Utah, University of Utah, Salt Lake City, Utah \\ (Received March 29, 2007; Final Revision January 23, 2008; Accepted January 29, 2008)
}

\begin{abstract}
A detailed morphometric analysis of the cerebellum in autism with and without macrocephaly. Four subject groups ( $N=65$; male; IQs $\geq 65$; age 7 to 26 years) were studied with quantitative MRI; normocephalic and macrocephalic individuals with autism without mental retardation were compared to normocephalic and benign macrocephalic typically developing individuals. Total cerebellum volumes and surface areas of four lobular midsagittal groups were measured. Independent $t$-tests between autism and control subjects matched for head size revealed no significant differences. Multivariate analyses of variance were also performed, using the diagnostic group as the fixed factor, cerebellar measures as the dependent variables and total intracranial volume, total brain volume, age, verbal IQ, and performance IQ as covariates. No significant differences were found; however, a trend was noted in which macrocephalic individuals with autism consistently exhibited slightly smaller cerebellar volume or surface area when compared to individuals with benign macrocephaly. In autism, with and without macrocephaly, cerebellar structures were found to be proportional to head size and did not differ from typically developing subjects.
\end{abstract}

(JINS, 2008, 14, 401-413.)

Keywords: Neuroimaging, Autism, Cerebellar, Brain volumes, Head size

\section{INTRODUCTION}

Historically, the cerebellum was believed to function primarily in background motor control and the coordination of movement (Thach, 1996; Thach et al., 1992). The cerebellum participates in a wide array of cognitive, language, motor, and emotional functions (Cabeza \& Nyberg, 2000; Highstein \& Thach, 2002; Schmahmann \& Caplan, 2006). Autism is a complex neurodevelopmental disorder with core features of language impairment, deficits in social behavior, and the presence of stereotypic, repetitive behaviors, and interests (American Psychiatric Association, 1994). All of these neurobehavioral features may be influenced by the

Correspondence and reprint requests to: Erin D. Bigler, Ph.D., Departments of Psychology and Neuroscience, 1001 SWKT, Brigham Young University, Provo, Utah 84602. E-mail: erin_bigler@byu.edu cerebellum (Allen \& Courchesne, 2003; Courchesne, 1999; Highstein \& Thach, 2002). As a result, the cerebellum and potential errors in its development have become central in various types of autism research, however, how neuropathological processes underlying autism affect cerebellar morphology is not yet understood, despite the numerous studies that have focused on this part of the brain (Abell et al., 1999; Allen et al., 2004; Baron-Cohen, 2004; Bauman \& Kemper, 2005; Belmonte et al., 2004; Brambilla et al., 2003; Ciesielski \& Knight, 1994; Courchesne et al., 1987; Ekman et al., 1991; Gaffney et al., 1987; Garber \& Ritvo, 1992; Hardan et al., 2001a; Hashimoto et al., 1993; Holttum et al., 1992; Levitt et al., 1999; Manes et al., 1999; Palmen et al., 2004; Piven, 1997; Piven et al., 1992; Rumsey et al., 1988; Saitoh et al., 1995; Spanos et al., 2007). Past studies have found "hypoplasia," "hyperplasia," and no volumetric or area differences in the cerebellum in autism. The reasons 
for the inconsistent findings are not clear but probably reflect the disorder's heterogeneity, maturational differences, the complexities of morphometric-neurobehavioral relationships, and differences in neuroimaging and measurement techniques.

Heterogenic aspects of autism that may affect cerebellum morphology include wide variations in head and brain size and IQ. An increased rate of macrocephaly (defined as $>1.88 \mathrm{SD}$ above the mean for age) is one of the most replicated findings in autism (Lainhart et al., 2005). Even when known medical causes of autism are excluded and idiopathic autism is the focus of study, rates of macrocephaly are increased to $20 \%$ on average (Davidovitch et al., 1996; Fidler et al., 2000; Fombonne et al., 1999; Gillberg \& de Souza, 2002; Lainhart et al., 1997; Miles et al., 2000; Stevenson et al., 1997; Woodhouse et al., 1996). In typically developing children and adults, cerebellar size is proportionally scaled to total brain volume (TBV) (Berquin et al., 1998; Caviness et al., 1996; Giedd et al., 1996). Even individuals who were born prematurely and have overall smaller brain volumes have proportionately scaled cerebella (Peterson et al., 2000). IQ in individuals with autism ranges from superior general intelligence to profound mental retardation (Bertrand et al., 2001; Chakrabarti \& Fombonne, 2001). In typical development, cerebellar size is related to IQ, showing a small but significant positive correlation (Andreasen et al., 1993; Paradiso et al., 1997; Peterson et al., 2000). These relationships in typically developing individuals indicate the importance of considering IQ as well as increased prevalence of larger head and brain size in imaging studies of the cerebellum in autism.

Age is another important factor in morphometric study of the cerebellum in autism. Converging evidence suggests that autism is characterized by normal head size and brain volume at birth but abnormal rates of growth during infancy and early childhood (Courchesne et al., 2003; Courchesne et al., 2001; Lainhart et al., 1997; Sparks et al., 2002; Stevenson et al., 1997). During later childhood and adolescence, the increase in head size persists but brain volume "normalizes." In adults with autism, mean total brain volume does not differ from controls (Hardan et al., 2001b; Herbert et al., 2003; Lainhart et al., 2005). Macrocephaly may be a persistent residual marker of abnormal brain growth during early childhood in autism. Scaling of the cerebellum to total brain volume may vary with age. During early and later childhood, cerebellar volume appears to be proportionately scaled to total brain volume (Herbert et al., 2003; Sparks et al., 2002). During adolescence and young adulthood, preliminary findings suggest that cerebellar volume is larger than expected for brain volume (Hardan et al., 2001a). There may also be an age-related effect on white matter volumes in the brain, including the cerebellum (Herbert et al., 2003).

The purpose of this study was to examine regional and total cerebellar morphometry in subjects with autism while controlling for the important variables mentioned earlier. Given the known relationships between age, total and regional brain volumes, as well as the importance of con- trolling for IQ and the increased prevalence of macrocephaly in autism (see Lainhart et al., 2005), we examined regional and total cerebellar size in macrocephalic and normocephalic subjects with autism compared to typically developing individuals who were normocephalic or who had "benign" macrocephaly. Whether normocephalic or macrocephalic, subjects with autism and control subjects were matched on age, IQ, and grade level. Given the diversity of results in previous studies on the cerebellum in autism, we conservatively hypothesized that no clinically distinctive differences in cerebellar size, including cerebellar lobules, would be found when controlling for head and brain size, age, and IQ.

Based on occipital frontal head circumference (OFC), subjects with autism and macrocephaly were compared to typical developing individuals with "benign" macrocephaly and in a separate analysis, normocephalic subjects with autism were compared to normocephalic typical developing controls. The rationale for keeping these comparisons separate was that by using OFC measures to define the groups, no further statistical control was needed for head size, since cerebellar size was the dependent variable and further statistical control of head size may have adventitiously mitigated the effect of interest. In these analyses, all groups were compared using multivariate methods where head size was statistically controlled. The rationale for these analyses was to simultaneously compare all autism (i.e., macrocephalic and normocephalic) and control (i.e., macrocephalic and normocephalic) groups on cerebellar size, while controlling for known group differences in head size, IQ, and age.

\section{METHOD}

\section{Subjects and Assessment}

\section{Ascertainment}

Autism and comparison subjects, age 7 to 26 years, were actively recruited through the University of Utah's Child Psychiatry Section of the Department of Psychiatry over a four-year period (1997-2001) from community sources, including parent support groups, youth groups, and schools, and from clinic social skills groups (Bigler et al., 2007). All autism and comparison subjects were participants in a crosssectional study of brain morphometry, conducted by the University of Utah Collaborative Program of Excellence in Autism (CPEA). After complete description of the study to the subjects and their parents, written informed consent was obtained. Any human data included in this manuscript were obtained in strict compliance with the approved IRB regulations of our institutions.

\section{Subject groups}

It is important to study relatively homogenous groups of individuals with autism because autism associated with high 
versus low IQ and occurring in males versus females may differ in etiology (Szatmari, 1999) and/or neuroanatomy (Piven et al., 1996). In this study, all subjects were males and they were divided into two IQ groups depending on whether their performance IQs were $\geq$ or $<$ than 65 . This study focuses on cognitively higher-functioning males with idiopathic autism and typically developing control males who were either macrocephalic or normocephalic.

\section{Idiopathic autism}

Autism was rigorously diagnosed. The subject's mother was interviewed using the Autism Diagnostic Interview-Revised (ADI-R), a semi-structured, investigator-based interview with good reliability and validity (Lord et al., 1994). All subjects with autism were directly assessed by one of the investigators (JEL and SJO), who had established researchlevel reliability, using the Autism Diagnostic Observation Schedule-Generic (ADOS-G). The ADOS-G is a semistructured play and interview session designed to elicit social, communication, and stereotyped repetitive behaviors characteristic of autism (Lord et al., 2000). All autistic subjects met ADI-R, ADOS-G, and DSM-IV (American Psychiatric Association, 1994) criteria for autism. History, physical exam, Fragile-X gene testing, and karyotype, performed on all subjects, excluded medical causes of autism.

\section{Typical development}

Typically developing subjects, both normocephalic and benign macrocephalic, were recruited from the same ascertainment sources as the individuals with autism. They had no developmental, neurological, or severe psychiatric problems or disorders based on history, IQ, reading and language tests, physical examination, and structured psychiatric assessment. Pervasive developmental disorders were excluded in all comparison subjects by history, direct observation, and interview of the mother using the Family History Interview (FHI) for Disorders of Social Development and Cognition (Bolton et al., 1994; Folstein et al., 1999). The FHI was specifically designed to inquire about signs of autism-spectrum disorders and milder isolated autism-like features using the family history method.

\section{$I Q$}

Verbal skills are often diminished in autism (Rapin, 1999). In addition, there can be wide splits between verbal and performance IQ in autism, making full scale IQ difficult to interpret (Deutsch \& Joseph, 2003). Adaptive functioning can be low even in individuals with autism who have high IQ's. For these reasons, we classified subjects as on the basis of non-verbal abilities as measured by the performance intellectual quotient (PIQ) on either the Wechsler Intelligence Scale for Children-III (WISC-III) (Wechsler, 1991) or the Wechsler Adult Intelligence Scale-III (WAISIII) (Wechsler, 1997). All subjects had PIQs $\geq 65$.

\section{Head circumference}

Head circumference was measured in all subjects using the standardized methods and reference data described by Farkas et al. (1994). Normocephaly was defined as a head circumference $>3$ rd but $\leq 97$ th percentile for age and sex. Macrocephaly was defined as a head circumference $>97$ th percentile for age and sex (Roche et al., 1987).

\section{Neuroimaging}

Magnetic resonance (MR) images were acquired on a Marconi 1.5 Tesla Scanner as previously described in detail (Bigler et al., 2003). Axial 3D T1 ( $\mathrm{TE}=4.47 \mathrm{~ms}, \mathrm{TR}=13 \mathrm{~ms}$, flip angle $=20$, slice thickness $=1.2 \mathrm{~mm}, \mathrm{FOV}=25.6 \mathrm{~cm})$ and 3D T2 FSE Coronal ( $\mathrm{TE}=114 \mathrm{~ms}, \mathrm{TR}=3500 \mathrm{~ms}$, slice thickness $=1.5 \mathrm{~mm}, \mathrm{FOV}=25.6 \mathrm{~cm}$ ) weighted images were used for quantitative image analysis. In some cases, sedation was necessary and followed a strict clinical protocol approved by the IRB of the University of Utah and performed by an onsite faculty anesthesiologist (JL).

\section{Quantitative image analyses}

Detailed quantitative analyses of total cerebellum and gray and white matter volumes were performed by two independent raters. Cerebellar morphometrics were based on left, right, and total cerebellar volume measurements using the well-established methods of Hardan et al. (2001a) and surface area measurements included cerebellar lobules I-V, VI-VII, VIII, and IX-X following guidelines for their quantification as published in several studies (Courchesne, 1991, 1997, 1999; Courchesne et al., 1989; Courchesne et al., 1994; Courchesne et al., 1988; Murakami et al., 1989; Saitoh et al., 1995). Briefly, the co-registered $\mathrm{T}_{1}$ and $\mathrm{T}_{2}$ weighted images were segmented into white, gray, and CSF pixels using the ANALYZE (Robb, 1995, 2001) multispectral tool. Total brain volume consisted of the combination of white and gray matter summed. Total CSF was the sum of subarachnoid and ventricular CSF. By using the inner table of the skull as a landmark, total intracranial volume (TICV) was determined by the total sum of whole brain parenchyma and CSF. Cerebellum volumes $\left(\mathrm{cm}^{3}\right)$ were measured, using the aforementioned segmentation on the resliced sagittal view of the segmented volume, obtaining total gray, total white, and total combined gray and white matter volumes (see Fig. 1).

The most midsagittal slice was determined by using the clear separation of the lingual from the medullary velum as one of the intravermian landmarks. Once this landmark was ascertained, the most lateral aspects of the cerebellum were identified by using ANALYZE ${ }^{\circledR}$ (Robb, 1995, 2001) Ortho Sections-Volume Render Tool on the T1 coronal view. Using the midsagittal slice as a starting point, every sixth slice was then measured bilaterally including all aspects of the cerebellum irrespective of gray and white matter. Once the most lateral slice was obtained on each hemisphere, no further slices were measured and the volume was calculated. 


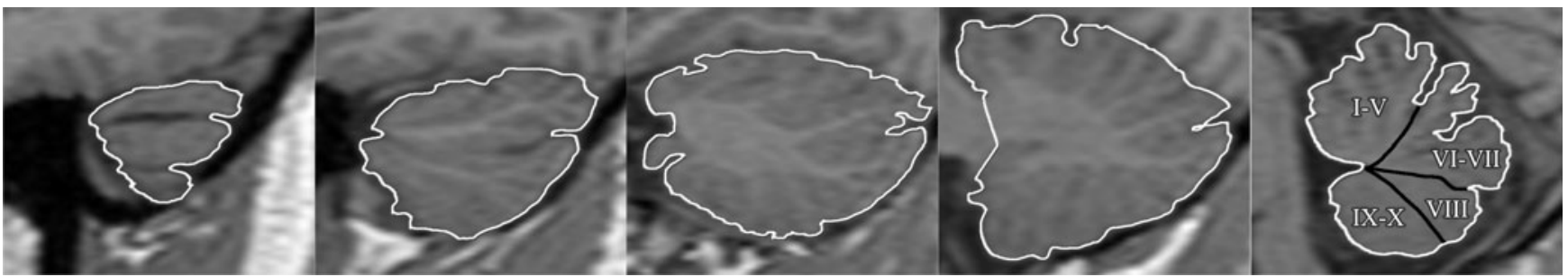

Fig. 1. $T_{1}$ weighted sagittal perspective showing cerebellar regions of interest of the left cerebellar hemisphere. Beginning with the most lateral slice (left most view) and ending with the midsagittal, volumetric measures (outline) were manually traced on every sixth slice (shown every 12th) from a segmented image of gray and white matter taken from co-registered $\mathrm{T}_{1}$ and $\mathrm{T}_{2}$ weighted images using the ANALYZE ${ }^{\circledR}$ multispectral tool. All classification areas were included irrespective of white and gray matter. All noncerebellar matter was excluded (i.e., occipital forceps and white matter stem). Surface areas of lobules I-V, VI-VII, VIII, and IX-X were taken in the midsagittal slice (right most view) in black. Demarcation for each lobule is described in the methods section of this paper.

\section{Area measurements}

Regions of interest were measured by outlining the vermis of the cerebellum on the most midsagittal slice (see Fig. 1). Manual tracing of the vermis was subdivided into four regions measured on the midsagittal slice: Lobules I-V (lingula, centralis, and culmen) were bounded by the superior medullary velum and the primary cerebellar fissure. Lobules VI-VII (declive, folium, and tuber), were bounded by the primary and the prepyramidal fissures. Lobule VIII (pyramis) was demarcated by the prepyramidal fissure and the secondary fissure. Lobules IX-X (uvula and nodulus) were divided by the secondary fissure and the inferior medullary velum. The junction of all vermian regions formed the apex of the fourth ventricle.

\section{Intra-rater and inter-rater reliability}

The accurate segmentation and tracing of the cerebellum is difficult to measure. Reliabilities were assessed using intraclass correlation coefficients. Mean intra-rater reliability across all structures was 0.97 (range of 0.94-0.99). High inter-rater reliability (0.99) was shown in total white matter volume, total gray matter volume, and total combined gray and white matter volumes measures. In addition, we demonstrated high agreement for total volumes with previous studies (Allen \& Courchesne, 2003; Hardan et al., 2001a; Makris et al., 2003).

\section{Statistical Methods}

Independent sample $t$-tests were used to compare the autism versus control separately for the normocephaly and macrocephaly comparison groups. For simultaneous comparison across all groups, we used a multivariate analysis of variance (MANOVA) to compare cerebellar measures between groups. In the multivariate analyses, the diagnostic group was the fixed factor, cerebellar measures the dependent variables, and total brain volume (TBV), performance IQ, and age were used as covariates. A separate but similar multivariate analysis was also run with identical dependent vari- ables using TICV as the covariate instead of total brain volume.

The distribution of mean cerebellar values was also examined as to whether autism or controls more consistently had larger values. For the cross-sectional cerebellar volume by age, unadjusted cerebellar volume was plotted by age at the time of scanning, with no correction for age (Allen et al., 2005).

\section{RESULTS}

\section{Normocephalic versus Macrocephalic Controls and Subjects with Autism}

The relationships between total brain volume, IQ, and cerebellar volume were examined and cerebellar volumes and areas in the four groups were compared with performance IQs of 65 or higher: 28 normocephalic and 13 macrocephalic subjects with autism were compared to 16 normocephalic and 8 benign macrocephalic typically developing subjects.

\section{Sample characteristics}

The age, IQ, and brain morphometric characteristics of the four groups are presented in Table 1. There were no significant differences in age, IQ, TBV, and TICV between the autism and typically developing normocephalic groups. Likewise, autism and control subjects meeting criteria for macrocephaly did not differ on any of these variables. When analyses were conducted excluding outliers (autism and control groups), no statistical differences were found, thus, outliers were included in all analyses.

\section{The relationship between total cerebellar volume, total brain volume, and performance $I Q$ in autism}

We examined the relationship between total cerebellar volume and TBV to better understand how the cerebellum is 
Table 1. Characteristics and total brain and intracranial volumes of the autism versus typically developing subjects

\begin{tabular}{|c|c|c|c|c|c|c|}
\hline & \multicolumn{4}{|c|}{$\begin{array}{l}\text { Normocephalic } \\
\qquad N=44\end{array}$} & \multirow[b]{3}{*}{$p$ value } & \multirow{3}{*}{$\begin{array}{l}\text { Effect sizes* } \\
\text { Partial Eta }\end{array}$} \\
\hline & \multicolumn{2}{|c|}{$\begin{array}{l}\text { Autism } \\
n=28\end{array}$} & \multicolumn{2}{|c|}{$\begin{array}{c}\text { Controls } \\
n=16\end{array}$} & & \\
\hline & Mean (SD) & Range & Mean (SD) & Range & & \\
\hline Age & $13.89(5.35)$ & $8-26$ & $13.94(5.40)$ & $7-25$ & .98 & .00 \\
\hline Performance IQ & $98.61(18.28)$ & $69-141$ & $102.00(13.53)$ & $74-123$ & .52 & .01 \\
\hline Verbal IQ & $95.36(25.06)$ & $57-134$ & $101.88(18.11)$ & $71-127$ & .37 & .02 \\
\hline TBV & $1349.33(109.66)$ & $1049.69-1523.19$ & $1324.75(80.66)$ & $1192.09-1461.17$ & .44 & .02 \\
\hline \multirow[t]{4}{*}{ TICV } & $1473.49(107.80)$ & $1202.21-1607.12$ & $1434.72(96.92)$ & $1272.93-1602.14$ & .24 & .03 \\
\hline & \multicolumn{4}{|c|}{$\begin{array}{l}\text { Macrocephalic } \\
\quad N=21\end{array}$} & \multirow{3}{*}{\multicolumn{2}{|c|}{$\begin{array}{l}\text { Effect sizes* } \\
\text { Partial Eta }^{2}\end{array}$}} \\
\hline & \multicolumn{2}{|c|}{$\begin{array}{l}\text { Autism } \\
n=13\end{array}$} & \multicolumn{2}{|c|}{$\begin{array}{c}\text { Controls } \\
n=8\end{array}$} & & \\
\hline & Mean (SD) & Range & Mean (SD) & Range & & \\
\hline Age & $12.69(4.25)$ & $7-19$ & $12.63(3.29)$ & $8-16$ & .98 & .00 \\
\hline Performance IQ & 109.15 (17.57) & $69-125$ & 117.88 (11.69) & $103-136$ & .23 & .08 \\
\hline Verbal IQ & $108.62(32.98)$ & $46-142$ & $123.00(10.90)$ & $111-138$ & .25 & .07 \\
\hline TBV & $1520.04(128.71)$ & $1348.01-1713.69$ & $1576.75(83.79)$ & $1501.82-1762.20$ & .28 & .06 \\
\hline TICV & $1634.62(146.24)$ & $1376.26-1874.98$ & $1718.23(100.98)$ & $1587.15-1926.77$ & .17 & .10 \\
\hline
\end{tabular}

Note. $\mathrm{SD}=$ Standard Deviation; $\mathrm{TBV}=$ Total Brain Volume, $\mathrm{TICV}=$ Total Intracranial Volume; $\mathrm{cm}^{3}=$ cubic centimeters.

*Reflects the group effect autism versus control subjects.

scaled to brain volume in autism. As shown in Figure 2, total cerebellar volume was positively and significantly related to total brain volume for autism and control groups. Generally, those subjects meeting criteria for macrocephaly had the largest cerebellum volume. The correlations were similar between the two groups. The findings on all analyses remained the same when TICV was used instead of TBV and when outliers were excluded.

Figure 3 shows the relationship between total cerebellar volume and performance IQ. When analyzed separately, all four groups exhibited generally positive correlations between PIQ and cerebellar volume. Combining the normocephalic and macrocephalic subjects with autism, the overall correlation between PIQ and cerebellar volume was significant $(r=.40, p=.01)$. In the combined sample of normocephalic and macrocephalic typically developing subjects the correlation was positive but only approached significance, likely because of the smaller sample size $(r=.34, p=.11)$. The correlations between PIQ and total cerebellar volume in the autism and typically developing subjects were similar.

\section{Total cerebellar volumes in autism}

Table 2 presents the unadjusted values for total cerebellar volume and total gray and white matter cerebellar volumes for the normocephalic and macrocephalic autism and typically developing subjects. Independent sample $t$-tests found no significant differences between groups. In addition, MANOVA analyses using age, PIQ, and either TBV or TICV as covariates, yielded no statistically significant findings.

\section{Midsagittal areas of vermal lobules}

Table 3 shows the unadjusted midsagittal measurements for the total vermal lobules area, gray matter area, and white matter area for the normocephalic and macrocephalic autism and typically developing samples. Once again, independent sample $t$-tests and MANOVA analyses yielded no statistically significant results.

An interesting observation was seen in the macrocephalic comparison, as shown in Table 3. All but one of the unadjusted volume and area comparisons of macrocephalic autism and benign macrocephalic typically developing subjects showed a smaller measurement for the autism group (see Tables 2 and 3). This suggests that there may be a subtle diminution in the size of the cerebellum of subjects with autism and macrocephaly where autism is associated with slightly less surface area and/or volume. This finding was not present when the normocephalic autism and normocephalic typically developing subjects were compared.

\section{Total cerebellar white and gray matter volume versus age in autism}

Cross-sectional, age-related changes in cerebellar white and gray matter volumes were explored first by plots of volume by subject age at the time of the scan as presented in Figure 4 . In the autism and typically developing subjects, cerebellar white matter volume increased with age, but the correlation was only significant in the typically developing subjects $(r=.40, p \leq .05)$. The difference between the two 
Autism and Control

Normocephalic and Macrocephalic Subjects

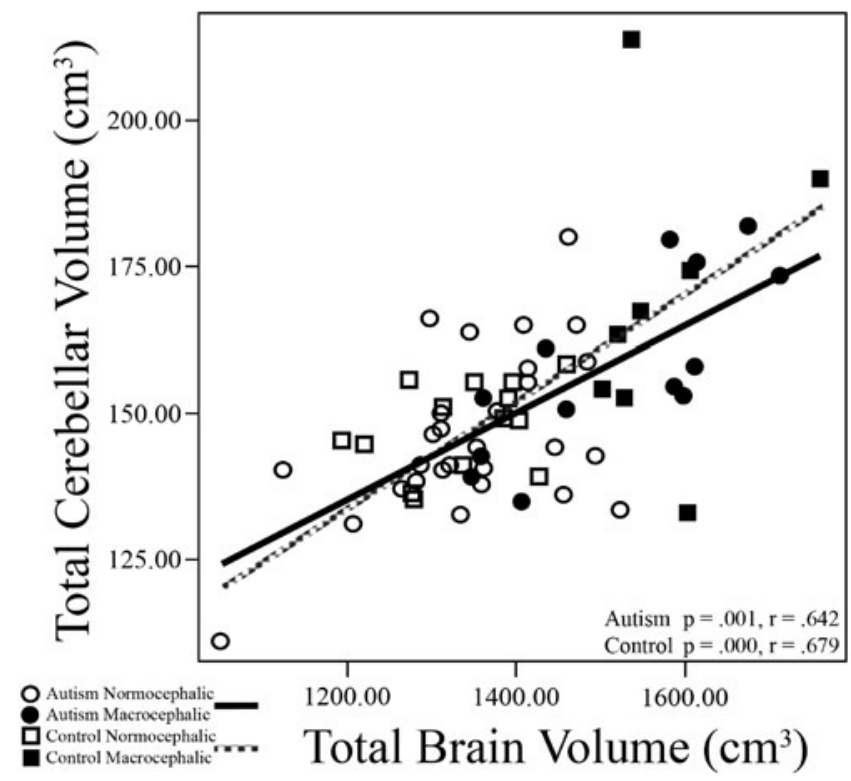

Fig. 2. Total cerebellar volume by total brain volume in normocephalic and macrocephalic autism and typically developing subjects. Macrocephalic (filled circle) and normocephalic autism (empty circle) subjects and macrocephalic comparison (filled square) and normocephalic comparison (empty square) subjects are shown with means and total brain volume scatter by $\mathrm{cm}^{3}$. Regression lines are included comparing combined autism subjects (solid line) with combined comparison subjects (dashed line).

slopes approached significance $(F=3.51, p=.07)$, suggesting a possible difference in the trajectory of white matter development in the cerebellum in autism. Cerebellar gray matter volume decreased with age in both controls and those with autism, but only approached significance in the subjects with autism.

\section{Total cerebellar volume and white and gray matter volumes in all groups}

Figure 5 shows the cerebellar morphometric distributions for the autism and comparison subgroups for total cerebellar volume and white and gray matter volumes. No significant group differences were found using MANOVA techniques, with diagnostic group as the fixed factor; cerebellar measures as the dependent variables and TBV; performance IQ; and age as covariates, when the outliers were removed and statistical analysis was performed

Because another study found increased cerebellar volume relative to total brain volume in adolescents and adults with autism compared to controls (Hardan et al., 2001b), we repeated the analysis on the autism and comparison subjects, 12 years of age or older, in our samples. The results again revealed no volumetric differences between individuals with autism and controls.

\section{Autism and Control} Normocephalic and Macrocephalic Subjects

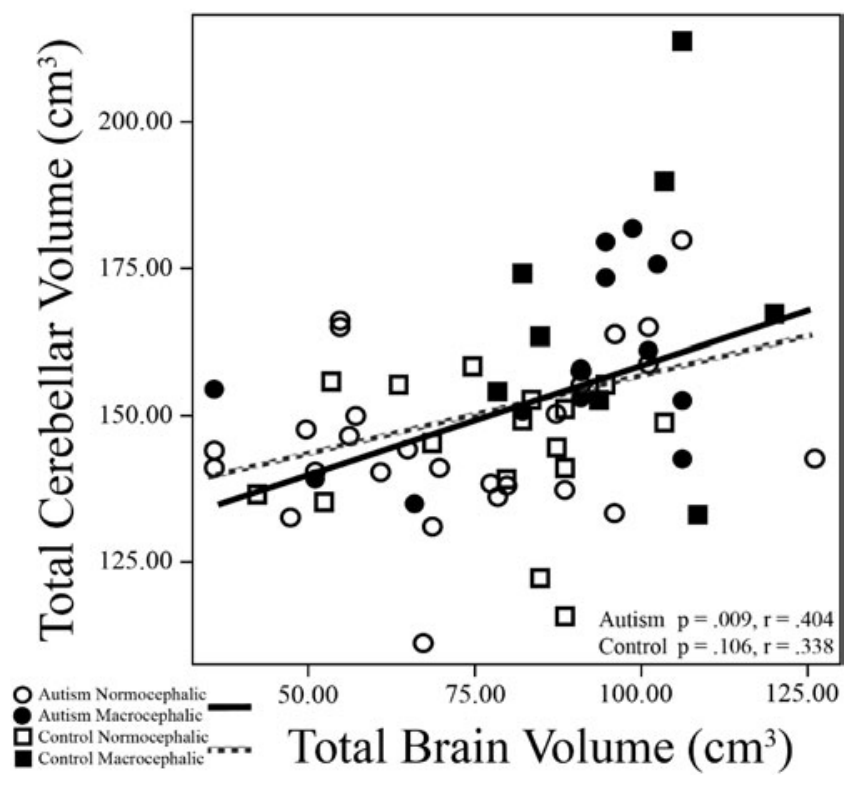

Fig. 3. Total cerebellar volume $\left(\mathrm{cm}^{3}\right)$ by performance IQ in normocephalic and macrocephalic autism and typically developing subjects. Macrocephalic (filled circle) and normocephalic autism (empty circle) subjects and macrocephalic comparison (filled square) and normocephalic comparison (empty square) subjects are shown with means and performance IQ scatter. Regression lines are included comparing combined autism subjects (solid line) with combined comparison subjects (dashed line).

\section{Distributions of total cerebellar volume and vermal lobule areas in autism}

Figure 6 combines all subjects with autism and compares them to all control subjects demonstrating no significant overall difference in total cerebellar volume between those with or without autism.

\section{DISCUSSION}

There is considerable evidence that the cerebellum is functionally and histologically abnormal in autism (Ahsgren et al., 2005; Bauman \& Kemper, 2005; Belmonte \& Carper, 2006; Nayate et al., 2005). The standard quantitative MRI analyses performed in this study, however, demonstrated no overall cerebellar size differences in subjects with autism after controlling for age, head-size variation, and IQ. It is important to note that given the multiple cerebellar measurements, we have taken a conservative approach to the findings; however, given that none of the individual measurements were significantly different, we feel that we are not missing significance by multiple comparisons.

The current study is important because control subjects included typically developing individuals with benign macrocephaly so that the proportion of cases with OFC-defined 
Table 2. Unadjusted cerebellar volumes $\left(\mathrm{cm}^{3}\right)$ in autism versus typically developing subjects

\begin{tabular}{|c|c|c|c|c|c|c|}
\hline \multirow[b]{4}{*}{ Cerebellar Measure } & \multicolumn{4}{|c|}{$\begin{array}{l}\text { Cerebellar volume }\left(\mathrm{cm}^{3}\right) \\
\qquad N=65\end{array}$} & \multirow[b]{4}{*}{$p$ value } & \multirow{4}{*}{$\begin{array}{l}\text { Effect sizes* } \\
\text { Partial Eta }\end{array}$} \\
\hline & \multicolumn{2}{|c|}{$\begin{array}{l}\text { Normocephalic } \\
\quad N=44\end{array}$} & \multicolumn{2}{|c|}{$\begin{array}{l}\text { Macrocephalic } \\
\qquad N=21\end{array}$} & & \\
\hline & $\begin{array}{l}\text { Autism } \\
(n=28)\end{array}$ & $\begin{array}{l}\text { Controls } \\
(n=16)\end{array}$ & $\begin{array}{l}\text { Autism } \\
(n=13)\end{array}$ & $\begin{array}{l}\text { Controls } \\
(n=8)\end{array}$ & & \\
\hline & Mean (SD) & Mean (SD) & Mean (SD) & Mean (SD) & & \\
\hline Total & $146.60(13.96)$ & 144.37 (12.19) & 158.55 (15.39) & $168.86(24.81)$ & .45 & .01 \\
\hline Gray Matter & $110.88(14.39)$ & $110.09(11.52)$ & $120.78(12.38)$ & $126.23(18.51)$ & .71 & .00 \\
\hline White Matter & $35.72(8.23)$ & $34.28(9.40)$ & $37.77(8.41)$ & $42.63(12.90)$ & .78 & .00 \\
\hline
\end{tabular}

Note. $\mathrm{SD}=$ Standard Deviation $; \mathrm{cm}^{3}=$ cubic centimeters

*Reflects the group effect autism versus control subjects.

macrocephaly was similar in the autism and control groups. Plots of cerebellar volumes of the autism and control subjects in this study showed no unique distribution for the autism sample. Thus, at the gross level, no major volumetric or surface area findings distinguished the autism sample from the typically developing controls. Interesting relationships and observations in the autism group with macrocephaly were noted that may have a bearing on uncovering the role of the cerebellum in autism.
Several findings suggested that mechanisms resulting in macrocephaly in autism may have a subtle negative effect on cerebellar size, particularly on white matter of the vermal lobules. Macrocephalic subjects in our autism and typically developing groups had, as expected, the largest total cerebellar volumes. Overall, it seemed that the cerebellum was similarly scaled to total brain volume in the autism and typical control subjects. In the combined normocephalic and macrocephalic autism sample and in the combined typ-

Table 3. Unadjusted midsagittal area $\left(\mathrm{mm}^{2}\right)$ of vermal lobules in autism versus typically developing subjects

\begin{tabular}{|c|c|c|c|c|c|c|}
\hline \multirow[b]{4}{*}{ Lobular Region $\left(\mathrm{mm}^{2}\right)$} & \multicolumn{4}{|c|}{$\begin{array}{l}\text { Midsagittal area }\left(\mathrm{mm}^{2}\right) \\
\quad N=65\end{array}$} & \multirow[b]{4}{*}{$p$ value } & \multirow{4}{*}{$\begin{array}{l}\text { Effect sizes* } \\
\text { Partial Eta }\end{array}$} \\
\hline & \multicolumn{2}{|c|}{$\begin{array}{l}\text { Normocephalic } \\
\quad N=44\end{array}$} & \multicolumn{2}{|c|}{$\begin{array}{l}\text { Macrocephalic } \\
\qquad N=21\end{array}$} & & \\
\hline & $\begin{array}{l}\text { Autism } \\
(n=28)\end{array}$ & $\begin{array}{l}\text { Controls } \\
(n=16)\end{array}$ & $\begin{array}{l}\text { Autism } \\
(n=13)\end{array}$ & $\begin{array}{l}\text { Controls } \\
(n=8)\end{array}$ & & \\
\hline & Mean (SD) & Mean (SD) & Mean (SD) & Mean (SD) & & \\
\hline \multicolumn{7}{|l|}{$\mathrm{I}-\mathrm{V}$} \\
\hline Total & $460.02(66.51)$ & $456.94(54.79)$ & $472.46(44.65)$ & $517.19(70.41)$ & .42 & .01 \\
\hline Gray Matter & $416.96(65.21)$ & $417.72(51.83)$ & $436.77(44.55)$ & $458.38(63.92)$ & .60 & .00 \\
\hline White Matter & 43.05 (31.79) & $29.22(29.88)$ & $35.69(16.72)$ & $58.81(40.28)$ & .52 & .01 \\
\hline \multicolumn{7}{|l|}{ VI-VII } \\
\hline Total & $311.20(80.63)$ & $322.59(93.49)$ & $323.92(63.37)$ & $381.69(157.36)$ & .26 & .02 \\
\hline Gray Matter & $281.55(63.68)$ & $293.16(76.00)$ & $298.65(66.31)$ & 336.25 (130.97) & .31 & .02 \\
\hline White Matter & $29.64(32.54)$ & $29.44(21.74)$ & $25.27(14.61)$ & $45.44(34.45)$ & .36 & .01 \\
\hline \multicolumn{7}{|l|}{ VIII } \\
\hline Total & $192.68(48.70)$ & $194.47(56.93)$ & $184.46(28.24)$ & $201.75(26.14)$ & .56 & .01 \\
\hline Gray Matter & $173.98(38.47)$ & $173.69(52.24)$ & $169.58(26.18)$ & $179.81(31.19)$ & .76 & .00 \\
\hline White Matter & $18.70(21.08)$ & $21.00(16.42)$ & $14.88(11.17)$ & $21.94(20.01)$ & .41 & .01 \\
\hline \multicolumn{7}{|l|}{ IX-X } \\
\hline Total & $258.20(99.03)$ & $251.97(79.03)$ & $277.85(101.46)$ & $279.88(111.03)$ & .90 & .00 \\
\hline Gray Matter & $234.46(77.62)$ & $232.72(78.48)$ & $268.69(93.46)$ & $259.06(98.82)$ & .86 & .00 \\
\hline White Matter & $23.73(38.27)$ & $19.25(17.21)$ & $9.15(12.32)$ & $20.81(22.37)$ & .93 & .00 \\
\hline
\end{tabular}

Note. $\mathrm{SD}=$ Standard Deviation; $\mathrm{mm}^{2}=$ square millimeters.

*Reflects the group effect autism versus control subjects. 


\section{Autism and Control Normocephalic and Macrocephalic Subjects}
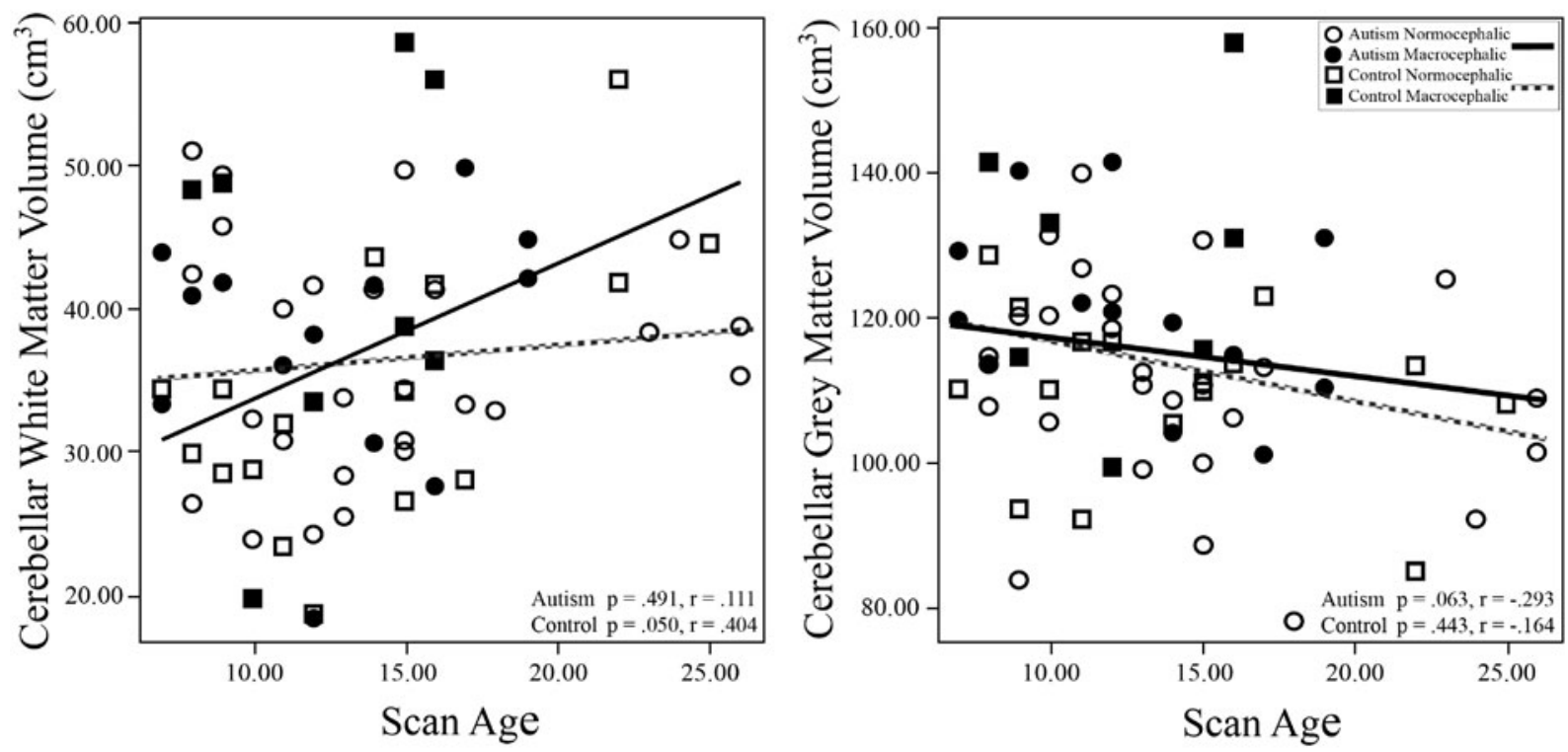

Fig. 4. Cerebellar white matter and gray matter volumes $\left(\mathrm{cm}^{3}\right)$ by age in normocephalic and macrocephalic autism and typically developing subjects. Macrocephalic (filled circle) and normocephalic autism (empty circle) subjects and macrocephalic comparison (filled square) and normocephalic comparison (empty square) subjects are shown with cerebellar white matter (left figure) and cerebellar gray matter (right figure) volume means $\mathrm{cm}^{3}$ by scan age. Regression lines for combined autism subjects (solid line) and comparison subjects (dashed line) are included for both cerebellar white matter and gray matter volumes.

ical control sample, the relationships between TBV and cerebellar volume were highly significant and robust. Whereas the absolute differences between subjects with autism with and without macrocephaly and their control counterparts were not significant, the macrocephalic subjects with autism consistently had slightly less cerebellar volumes and midsagittal surface areas than macrocephalic controls. There were a total of 15 separate analyses of either cerebellar volume or surface area. In 14 of those comparisons, the autism group with macrocephaly had less volume or surface area, an unlikely occurrence by chance. This pattern persisted even when small differences in total brain volume and PIQ between groups were controlled. Interestingly, the autism group with macrocephaly had the smallest white matter surface area for lobular regions VI-VII, VIII, IX-X of all four autism and typical control normocephalic and macrocephalic groups. High inter-subject variability and small sample sizes may have resulted in power too low to

Total, White and Grey Cerebellar Volume by Group

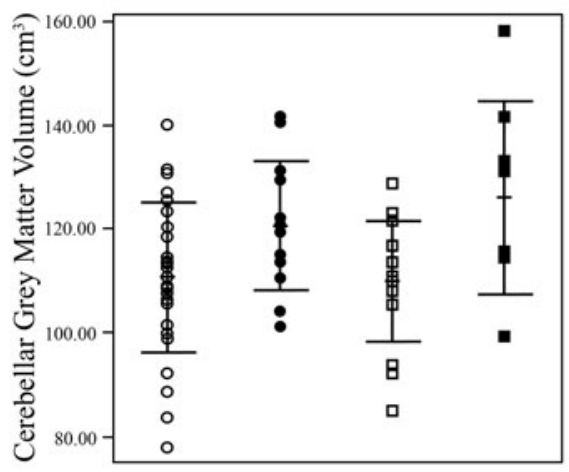

Diagnosis

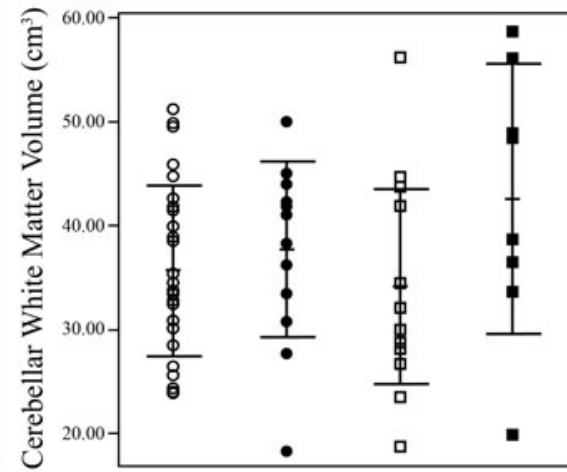

Diagnosis

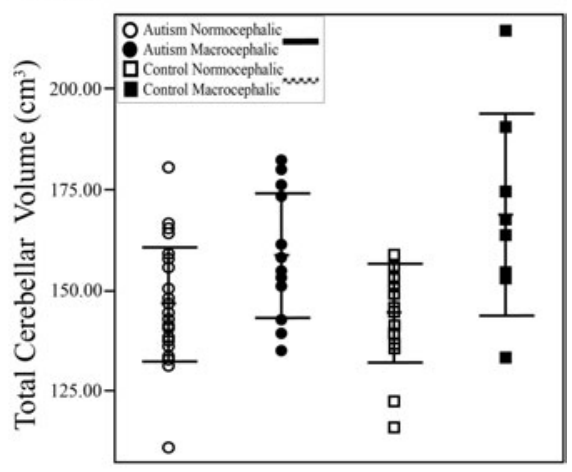

Diagnosis

Fig. 5. Total cerebellar volume and cerebellar white and gray matter volumes in autism and typically developing subjects. Total combined white and gray matter (right), total gray matter volume (left), and total white matter volume (center) are shown with means and scatter by $\mathrm{cm}^{3}$. 
detect significant differences in these comparisons. The findings are consistent with a recent study using a voxel-based method of analysis that found significantly reduced white matter in the cerebellum in autism (McAlonan et al., 2005), and interesting, when considering the finding of an inverse correlation between frontal lobe and cerebellum sizes in children with autism (Carper \& Courchesne, 2000). Growth patterns of the cerebellum early in childhood in autism, especially in those children with abnormal rates of early brain growth who develop macrocephaly, may explain how the development of the cerebellum and macrocephaly are related.

Age-related changes in the cerebellum appeared different in subjects with autism compared to the typically developing group. In typically developing controls, cerebellar white matter volume increased with age. No increase with age was evident in the subjects with autism. Cerebellar white matter development and maturation during adolescence and young adulthood may thus be aberrant in autism. In contrast, no age-by-group interaction was observed for cerebellar gray matter volume.

Understanding of the in-vivo neuropathology of the cerebellum in autism has been hindered by a lack of consistent findings. A consistent finding in postmortem histopathological studies is the decreased numbers of Purkinje cells in individuals with autism (Bailey et al., 1998; Bauman \& Kemper, 1985, 1986, 1990, 1994, 2003, 2005; Kemper \& Bauman, 1998, 2002; Lee et al., 2002; Martin-Ruiz et al., 2004; Ritvo

\section{Total Cerebellum Volume by Autism and Control Normocephalic and Macrocephalic Subjects}

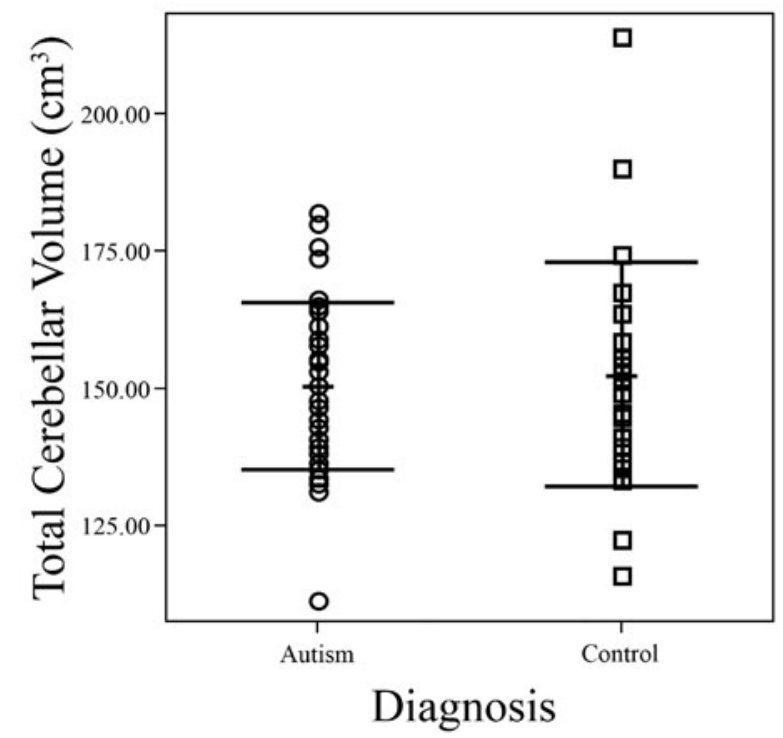

Fig. 6. The distribution of total cerebellar volumes in autism (circle) and comparison (square) subjects. The autism and comparison groups include both normocephalic and macrocephalic subjects. Total combined white and gray matter cerebellar volumes are shown with means and scatter by $\mathrm{cm}^{3}$. Standard deviation bars (solid black bars) of one are included. et al., 1986; Williams et al., 1980). Palmen et al. (2004) noted the high comorbidity of autism and mental retardation (at least $70 \%$ ) and found a decreased number of Purkinje cells in 21 of 29 neuropathological cases of the cerebellum. A relationship between the Purkinje cell abnormality and neuroimaging findings has not been established (Lee et al., 2002). Neuroimaging studies of the cerebellum in autism have been inconsistent (Acosta \& Pearl, 2004). Some researchers have found smaller cerebellar measurements, particularly in the vermis (Courchesne, 1991, 1997, 1999; Courchesne et al., 2001; Courchesne et al., 1989; Courchesne et al., 1994, 1995; Hashimoto et al., 1993; Murakami et al., 1989; Schaefer et al., 1996). One study found a significant increase in unadjusted cerebellar volume in autism, but the difference did not remain significant once total brain volume was controlled for (Herbert et al., 2003).

Other researchers have found no significant differences between autism and comparison groups (Elia et al., 2000; Garber \& Ritvo, 1992; Holttum et al., 1992; Kleiman et al., 1992; Piven et al., 1992; Piven et al., 1997; Sparks et al., 2002). Our study shows that factors other than diagnosis may be related to cerebellar volume and area in autism. The variable findings of past studies may have been related to significant inter-study variability in age, IQ, brain volume, and rate of macrocephaly in the autism samples. Recent studies by Courchesne et al. (2001) and Sparks et al. (2002) show that clinically significant volumetric differences in individuals with autism may occur in children younger than the subjects examined in our study and most other studies.

In our study, traditional quantitative volumetric and area methods did not show marked autism-control differences in the cerebellum. New morphometric and functional neuroimaging methods may find some differences. Functional neuroimaging studies have implicated the cerebellum in higher-order cognitive functions, of primary interest in autism, because some of the behavioral aspects of emotional regulation, language, and executive functioning are mediated by the cerebellum (Critchley et al., 2000; Desmond \& Fiez, 1998; Dolan, 1998; Leiner et al., 1995; Parsons et al., 1997; Schmahmann \& Sherman, 1998). fMRI differences of cerebellar activation in autism have been explored (Allen \& Courchesne, 2003). The subtle findings in vermal lobule white matter in the macrocephalic autism group in our study indicate the need for more detailed methods of examining white matter integrity in the cerebellum (see also Barnea-Goraly et al., 2004; Waiter et al., 2004, 2005).

There are several potential limitations of the current study. As with most autism studies, modest sample sizes probably limited the statistical power especially in the separate analysis of normocephalic and macrocephalic case and control subgroups. We believe, however, that our attempt at separate analysis based on OFC is an important first step in understanding how the increased rate of macrocephaly in autism affects regional brain morphometry. The results of our study are supported by visual inspection of the scatter plots in Figure 5 that show no substantial differences in total cerebellar volume and white and gray matter volumes 
between controls and subjects with autism. Though dividing the autism and control subjects into normocephalic and macrocephalic groups may have decreased the power of our study, the findings in the macrocephaly autism group are intriguing. They suggest that subjects with autism and macrocephaly may be a particularly informative group to include in studies. Larger samples of autism individuals with macrocephaly may shed light on subtle but important differences in the cerebellum of individuals with autism. Our examination of changes in cerebellar white and gray matter volume with age in autism is limited by the crosssectional nature of the data. Cross-sectional age-related findings result in hypotheses that need to be tested using a longitudinal design.

\section{CONCLUSIONS}

By matching autism and control samples on key cognitive and physical measurements along with age and statistically controlling for these potentially confounding variables, no major differences in cerebellar morphometry was found between subjects with autism and control subjects 7 to 26 years of age. In autism, with and without macrocephaly, cerebellar structures were generally proportional to head size and did not statistically differ from typically developing subjects with and without benign macrocephaly. Subjects with autism and macrocephaly consistently had the smallest cerebellar measurements. In non-mentally retarded subjects with autism and controls, cerebellar size was positively correlated with PIQ and generally proportional to overall brain volume.

\section{ACKNOWLEDGMENTS}

This work was supported by NICHD U19 HD35476 (University of Utah), the NICHD/NIDCD Collaborative Programs of Excellence in Autism (CPEA), the Ira Fulton Foundation, the Utah Autism Foundation, and Valley Mental Health. The technical assistance of Tracy Abildskov and the editorial assistance of Jo Ann Petrie are gratefully acknowledged. The authors thank the staff of the Utah Autism Research Program, particularly Michael Johnson, Jubel Morgan, Lori Krasny, Barbara Young, Dr. Sally J. Ozonoff (now of the UC Davis MIND Institute), Henry Buswell and Dr. Dennis Parker of the University of Utah Research Radiology. The authors particularly thank the children and adults who participated in this study and their parents.

\section{REFERENCES}

Abell, F., Krams, M., Ashburner, J., Passingham, R., Friston, K., Frackowiak, R., Happe, F., Frith, C., \& Frith, U. (1999). The neuroanatomy of autism: A voxel-based whole brain analysis of structural scans. Neuroreport, 10, 1647-1651.

Acosta, M.T. \& Pearl, P.L. (2004). Imaging data in autism: From structure to malfunction. Seminars in Pediatric Neurology, 11, 205-213.

Ahsgren, I., Baldwin, I., Goetzinger-Falk, C., Erikson, A., Flodmark, O., \& Gillberg, C. (2005). Ataxia, autism, and the cerebellum: A clinical study of 32 individuals with congenital ataxia. Developmental Medicine and Child Neurology, 47, 193-198.

Allen, G. \& Courchesne, E. (2003). Differential effects of developmental cerebellar abnormality on cognitive and motor functions in the cerebellum: An fMRI study of autism. American Journal of Psychiatry, 160, 262-273.

Allen, G., Muller, R.A., \& Courchesne, E. (2004). Cerebellar function in autism: Functional magnetic resonance image activation during a simple motor task. Biological Psychiatry, 56, 269-278.

Allen, J.S., Bruss, J., Brown, C.K., \& Damasio, H. (2005). Normal neuroanatomical variation due to age: The major lobes and a parcellation of the temporal region. Neurobiology of Aging, 26 , 1245-1260; discussion 1279-1282.

American Psychiatric Association. (1994). Diagnostic and statistical manual of mental disorders: DSM-IVTM (4th ed.). Washington, D.C.: American Psychiatric Association.

Andreasen, N.C., Flaum, M., Swayze 2nd, V., O'Leary, D.S., Alliger, R., Cohen, G., Ehrhardt, J., \& Yuh, W.T. (1993). Intelligence and brain structure in normal individuals. American Journal of Psychiatry, 150, 130-134.

Bailey, A., Luthert, P., Dean, A., Harding, B., Janota, I., Montgomery, M., Rutter, M., \& Lantos, P. (1998). A clinicopathological study of autism. Brain, 121, 889-905.

Barnea-Goraly, N., Kwon, H., Menon, V., Eliez, S., Lotspeich, L., \& Reiss, A.L. (2004). White matter structure in autism: Preliminary evidence from diffusion tensor imaging. Biological Psychiatry, 55, 323-326.

Baron-Cohen, S. (2004). The cognitive neuroscience of autism. Journal of Neurology, Neurosurgery and Psychiatry, 75, 945-948.

Bauman, M.L. \& Kemper, T.L. (1985). Histoanatomic observations of the brain in early infantile autism. Neurology, 35, $866-874$.

Bauman, M.L. \& Kemper, T.L. (1986). Developmental cerebellar abnormalities: A consistent finding in early infantile autism. Neurology, 36 (Suppl. 1), 190.

Bauman, M.L. \& Kemper, T.L. (1990). Limbic and cerebellar abnormalities are also present in an autistic child of normal intelligence. Neurology, 40 (Suppl. 1), 359.

Bauman, M.L. \& Kemper, T.L. (1994). Neuroanatomic observations of the brain in autism. In M.L. Bauman \& T.L. Kemper (Eds.), The Neurobiology of Autism, (pp. 119-145). Baltimore, MD: John Hopkins University Press.

Bauman, M.L. \& Kemper, T.L. (2003). The neuropathology of the autism spectrum disorders: What have we learned? In G. Bock \& J. Goode (Eds.), Symposium on Autism: Neural Basis and Treatment Possibilities, Vol. 251 (pp. 112-128, 281-297). London: Novartis Foundation.

Bauman, M.L. \& Kemper, T.L. (2005). Neuroanatomic observations of the brain in autism: A review and future directions. International Journal of Developmental Neuroscience, 23, 183-187.

Belmonte, M.K., Allen, G., Beckel-Mitchener, A., Boulanger, L.M., Carper, R.A., \& Webb, S.J. (2004). Autism and abnormal development of brain connectivity. Journal of Neuroscience, 24, 9228-9231.

Belmonte, M.K. \& Carper, R.A. (2006). Monozygotic twins with Asperger syndrome: Differences in behaviour reflect variations in brain structure and function. Brain and Cognition, 61, 110-121.

Berquin, P.C., Giedd, J.N., Jacobsen, L.K., Hamburger, S.D., Krain, A.L., Rapoport, J.L., \& Castellanos, F.X. (1998). Cerebellum 
in attention-deficit hyperactivity disorder: A morphometric MRI study. Neurology, 50, 1087-1093.

Bertrand, J., Mars, A., Boyle, C., Bove, F., Yeargin-Allsopp, M., \& Decoufle, P. (2001). Prevalence of autism in a United States population: The Brick Township, New Jersey, investigation. Pediatrics, 108, 1155-1161.

Bigler, E.D., Mortensen, S., Neeley, E.S., Ozonoff, S., Krasny, L., Johnson, M., Lu, J., Provencal, S.L., McMahon, W., \& Lainhart, J.E. (2007). Superior temporal gyrus, language function, and autism. Developmental Neuropsychology, 31, 217238.

Bigler, E.D., Tate, D.F., Neeley, E.S., Wolfson, L.J., Miller, M.J., Rice, S.A., Cleavinger, H., Anderson, C., Coon, H., Ozonoff, S., Johnson, M., Dinh, E., Lu, J., Mc Mahon, W., \& Lainhart, J.E. (2003). Temporal lobe, autism, and macrocephaly. American Journal of Neuroradiology, 24, 2066-2076.

Bolton, P., MacDonald, H., Pickles, A., Rios, P., Goode, S., Crowson, M., Bailey, A., \& Rutter, M. (1994). A case-control family history study of autism. Journal of Child Psychology and Psychiatry and Allied Disciplines, 35, 877-900.

Brambilla, P., Hardan, A., di Nemi, S.U., Perez, J., Soares, J.C., \& Barale, F. (2003). Brain anatomy and development in autism: Review of structural MRI studies. Brain Research Bulletin, 61, 557-569.

Cabeza, R. \& Nyberg, L. (2000). Imaging cognition II: An empirical review of 275 PET and $\mathrm{AMRI}$ studies. Journal of Cognitive Neuroscience, 12, 1-47.

Carper, R.A. \& Courchesne, E. (2000). Inverse correlation between frontal lobe and cerebellum sizes in children with autism. Brain, 123 (Pt 4), 836-844.

Caviness, V.S., Jr., Kennedy, D.N., Richelme, C., Rademacher, J., \& Filipek, P.A. (1996). The human brain age 7-11 years: A volumetric analysis based on magnetic resonance images. Cerebral Cortex, 6, 726-736.

Chakrabarti, S. \& Fombonne, E. (2001). Pervasive developmental disorders in preschool children. Journal of the American Medical Association, 285, 3093-3099.

Ciesielski, K.T. \& Knight, J.E. (1994). Cerebellar abnormality in autism: A nonspecific effect of early brain damage? Acta Neurobiologiae Experimentalis, 54, 151-154.

Courchesne, E. (1991). Neuroanatomic imaging in autism. Pediatrics, 87(5 Pt 2), 781-790.

Courchesne, E. (1997). Brainstem, cerebellar and limbic neuroanatomical abnormalities in autism. Current Opinion in Neurobiology, 7, 269-278.

Courchesne, E. (1999). An MRI study of autism: The cerebellum revisited. Neurology, 52, 1106-1107.

Courchesne, E., Carper, R., \& Akshoomoff, N. (2003). Evidence of brain overgrowth in the first year of life in autism. Journal of the American Medical Association, 290, 337-344.

Courchesne, E., Hesselink, J.R., Jernigan, T.L., \& YeungCourchesne, R. (1987). Abnormal neuroanatomy in a nonretarded person with autism. Unusual findings with magnetic resonance imaging. Archives of Neurology, 44, 335-341.

Courchesne, E., Karns, C.M., Davis, H.R., Ziccardi, R., Carper, R.A., Tigue, Z.D., Chisum, H.J., Moses, P., Pierce, K., Lord, C., Lincoln, A.J., Pizzo, S., Schreibman, L., Haas, R.H., Akshoomoff, N.A., \& Courchesne, R.Y. (2001). Unusual brain growth patterns in early life in patients with autistic disorder: An MRI study. Neurology, 57, 245-254.

Courchesne, E., Press, G.A., Murakami, J., Berthoty, D., Grafe, M., Wiley, C.A., \& Hesselink, J.R. (1989). The cerebellum in sagittal plane-anatomic-MR correlation: 1 . The vermis. American Journal of Roentgenology, 153, 829-835.

Courchesne, E., Townsend, J., \& Saitoh, O. (1994). The brain in infantile autism: Posterior fossa structures are abnormal. Neurology, 44, 214-223.

Courchesne, E., Townsend, J., \& Saitoh, O. (1995). The cerebellum and autism: Reply from the authors. Neurology, 45, 399-402.

Courchesne, E., Yeung-Courchesne, R., Press, G.A., Hesselink, J.R., \& Jernigan, T.L. (1988). Hypoplasia of cerebellar vermal lobules VI and VII in autism. New England Journal of Medicine, 318, 1349-1354.

Critchley, H.D., Daly, E.M., Bullmore, E.T., Williams, S.C., Van Amelsvoort, T., Robertson, D.M., Rowe, A., Phillips, M., McAlonan, G., Howlin, P., \& Murphy, D.G. (2000). The functional neuroanatomy of social behaviour: Changes in cerebral blood flow when people with autistic disorder process facial expressions. Brain, 123 (Pt 11), 2203-2212.

Davidovitch, M., Patterson, B., \& Gartside, P. (1996). Head circumference measurements in children with autism. Journal of Child Neurology, 11, 389-393.

Desmond, J.E. \& Fiez, J.A. (1998). Lesion analysis in neuropsychology. Trends in Cognitive Science, 2, 355-362.

Deutsch, C.K. \& Joseph, R.M. (2003). Brief report: Cognitive correlates of enlarged head circumference in children with autism. Journal of Autism and Developmental Disorders, 33, 209-215.

Dolan, R.J. (1998). A cognitive affective role for the cerebellum. Brain, 121 (Pt 4), 545-546.

Ekman, G., de Chateau, P., Marions, O., Sellden, H., Wahlund, L.O., \& Wetterberg, L. (1991). Low field magnetic resonance imaging of the central nervous system in 15 children with autistic disorder. Acta Paediatrica Scandinavica, 80, 243-247.

Elia, M., Ferri, R., Musumeci, S.A., Panerai, S., Bottitta, M., \& Scuderi, C. (2000). Clinical correlates of brain morphometric features of subjects with low-functioning autistic disorder. Journal of Child Neurology, 15, 504-508.

Farkas, L.G., Hreczko, T.A., \& Katie, M.J. (1994). Craniofacial norms in North American Caucasians from birth to young adulthood. In L.G. Farkas (Ed.), Anthropometry of the Head and Face. New York: Raven Press.

Fidler, D.J., Bailey, J.N., \& Smalley, S.L. (2000). Macrocephaly in autism and other pervasive developmental disorders. Developmental Medicine and Child Neurology, 42, 737-740.

Folstein, S.E., Santangelo, S.L., Gilman, S.E., Piven, J., Landa, R., Lainhart, J., Hein, J., \& Wzorek, M. (1999). Predictors of cognitive test patterns in autism families. Journal of Child Psychology and Psychiatry, and Allied Disciplines, 40, 1117-1128.

Fombonne, E., Roge, B., Claverie, J., Courty, S., \& Fremolle, J. (1999). Microcephaly and macrocephaly in autism. Journal of Autism and Developmental Disorders, 29, 113-119.

Gaffney, G.R., Tsai, L.Y., Kuperman, S., \& Minchin, S. (1987). Cerebellar structure in autism. American Journal of Diseases of Children, 141, 1330-1332.

Garber, H.J. \& Ritvo, E.R. (1992). Magnetic resonance imaging of the posterior fossa in autistic adults. American Journal of Psychiatry, 149, 245-247.

Giedd, J.N., Snell, J.W., Lange, N., Rajapakse, J.C., Casey, B.J., Kozuch, P.L., Vaituzis, A.C., Vauss, Y.C., Hamburger, S.D., Kaysen, D., \& Rapoport, J.L. (1996). Quantitative magnetic resonance imaging of human brain development: Ages 4-18. Cerebral Cortex, 6, 551-560. 
Gillberg, C. \& de Souza, L. (2002). Head circumference in autism, asperger syndrome, and ADHD: A comparative study. Developmental Medicine and Child Neurology, 44, 296-300.

Hardan, A.Y., Minshew, N.J., Harenski, K., \& Keshavan, M.S. (2001a). Posterior fossa magnetic resonance imaging in autism. Journal of the American Academy of Child and Adolescent Psychiatry, 40, 666-672.

Hardan, A.Y., Minshew, N.J., Mallikarjuhn, M., \& Keshavan, M.S. (2001b). Brain volume in autism. Journal of Child Neurology, 16, 421-424.

Hashimoto, T., Tayama, M., Miyazaki, M., Murakawa, K., Shimakawa, S., Yoneda, Y., \& Kuroda, Y. (1993). Brainstem involvement in high functioning autistic children. Acta Neurologica Scandinavica, 88, 123-128.

Herbert, M.R., Ziegler, D.A., Deutsch, C.K., O’Brien, L.M., Lange, N., Bakardjiev, A., Hodgson, J., Adrien, K.T., Steele, S., Makris, N., Kennedy, D., Harris, G.J., \& Caviness, V.S., Jr. (2003). Dissociations of cerebral cortex, subcortical and cerebral white matter volumes in autistic boys. Brain, 126(Pt 5), 1182-1192.

Highstein, S.M. \& Thach, W.T. (Eds.). (2002). The cerebellum: Recent developments in cerebellar research. New York: New York Academy of Sciences.

Holttum, J.R., Minshew, N.J., Sanders, R.S., \& Phillips, N.E. (1992). Magnetic resonance imaging of the posterior fossa in autism. Biological Psychiatry, 32, 1091-1101.

Kemper, T.L. \& Bauman, M.L. (1998). Neuropathology of infantile autism. Journal of Neuropathology and Experimental Neurology, 57, 645-652.

Kemper, T.L. \& Bauman, M.L. (2002). Neuropathology of infantile autism. Molecular Psychiatry, 7 (Suppl. 2), S12-13.

Kleiman, M.D., Neff, S., \& Rosman, N.P. (1992). The brain in infantile autism: Are posterior fossa structures abnormal? Neurology, 42, 753-760.

Lainhart, J.E., Lazar, M., Alexander, A., \& Bigler, E.D. (2005). The brain during life in Autism: Advances in neuroimaging research. Hauppauge, NY: NOVA Science Publishers, Inc.

Lainhart, J.E., Piven, J., Wzorek, M., Landa, R., Santangelo, S.L., Coon, H., \& Folstein, S.E. (1997). Macrocephaly in children and adults with autism. Journal of the American Academy of Child and Adolescent Psychiatry, 36, 282-290.

Lee, M., Martin-Ruiz, C., Graham, A., Court, J., Jaros, E., Perry, R., Iversen, P., Bauman, M., \& Perry, E. (2002). Nicotinic receptor abnormalities in the cerebellar cortex in autism. Brain, 125 (Pt 7), 1483-1495.

Leiner, H.C., Leiner, A.L., \& Dow, R.S. (1995). The underestimated cerebellum. Human Brain Mapping, 2, 244-254.

Levitt, J.G., Blanton, R., Capetillo-Cunliffe, L., Guthrie, D., Toga, A., \& McCracken, J.T. (1999). Cerebellar vermis lobules VIII-X in autism. Progress in Neuro-Psychopharmacology \& Biological Psychiatry, 23, 625-633.

Lord, C., Risi, S., Lambrecht, L., Cook, E.H., Jr., Leventhal, B.L., DiLavore, P.C., Pickles, A., \& Rutter, M. (2000). The autism diagnostic observation schedule-generic: A standard measure of social and communication deficits associated with the spectrum of autism. Journal of Autism and Developmental Disorders, 30, 205-223.

Lord, C., Rutter, M., \& Le Couteur, A. (1994). Autism Diagnostic Interview-Revised: A revised version of a diagnostic interview for caregivers of individuals with possible pervasive developmental disorders. Journal of Autism and Developmental Disorders, 24, 659-685.

Makris, N., Hodge, S.M., Haselgrove, C., Kennedy, D.N., Dale,
A., Fischl, B., Rosen, B.R., Harris, G., Caviness Jr., V.S., \& Schmahmann, J.D. (2003). Human cerebellum: Surface-assisted cortical parcellation and volumetry with magnetic resonance imaging. Journal of Cognitive Neuroscience, 15, 584-599.

Manes, F., Piven, J., Vrancic, D., Nanclares, V., Plebst, C., \& Starkstein, S.E. (1999). An MRI study of the corpus callosum and cerebellum in mentally retarded autistic individuals. Journal of Neuropsychiatry and Clinical Neurosciences, 11, 470-474.

Martin-Ruiz, C.M., Lee, M., Perry, R.H., Baumann, M., Court, J.A., \& Perry, E.K. (2004). Molecular analysis of nicotinic receptor expression in autism. Brain Research. Molecular Brain Research, 123, 81-90.

McAlonan, G.M., Cheung, V., Cheung, C., Suckling, J., Lam, G.Y., Tai, K.S., Yip, L., Murphy, D.G., \& Chua, S.E. (2005). Mapping the brain in autism. A voxel-based MRI study of volumetric differences and intercorrelations in autism. Brain, $128(\mathrm{Pt}$ 2), 268-276.

Miles, J.H., Hadden, L.L., Takahashi, T.N., \& Hillman, R.E. (2000). Head circumference is an independent clinical finding associated with autism. American Journal of Medical Genetics, 95, 339-350.

Murakami, J.W., Courchesne, E., Press, G.A., Yeung-Courchesne, R., \& Hesselink, J.R. (1989). Reduced cerebellar hemisphere size and its relationship to vermal hypoplasia in autism. Archives of Neurology, 46, 689-694.

Nayate, A., Bradshaw, J.L., \& Rinehart, N.J. (2005). Autism and asperger's disorder: Are they movement disorders involving the cerebellum and/or basal ganglia? Brain Research Bulletin, 67, 327-334.

Palmen, S.J., van Engeland, H., Hof, P.R., \& Schmitz, C. (2004). Neuropathological findings in autism. Brain, 127 (Pt 12), 2572-2583.

Paradiso, S., Andreasen, N.C., O'Leary, D.S., Arndt, S., \& Robinson, R.G. (1997). Cerebellar size and cognition: Correlations with IQ, verbal memory and motor dexterity. Neuropsychiatry, Neuropsychology, and Behavioral Neurology, 10, 1-8.

Parsons, L.M., Bower, J.M., Gao, J.H., Xiong, J., Li, J., \& Fox, P.T. (1997). Lateral cerebellar hemispheres actively support sensory acquisition and discrimination rather than motor control. Learning and Memory, 4, 49-62.

Peterson, B.S., Vohr, B., Staib, L.H., Cannistraci, C.J., Dolberg, A., Schneider, K.C., Katz, K.H., Westerveld, M., Sparrow, S., Anderson, A.W., Duncan, C.C., Makuch, R.W., Gore, J.C., \& Ment, L.R. (2000). Regional brain volume abnormalities and long-term cognitive outcome in preterm infants. Journal of the American Medical Association, 284, 1939-1947.

Piven, J. (1997). The biological basis of autism. Current Opinion in Neurobiology, 7, 708-712.

Piven, J., Arndt, S., Bailey, J., \& Andreasen, N. (1996). Regional brain enlargement in autism: A magnetic resonance imaging study. Journal of the American Academy of Child and Adolescent Psychiatry, 35, 530-536.

Piven, J., Nehme, E., Simon, J., Barta, P., Pearlson, G., \& Folstein, S.E. (1992). Magnetic resonance imaging in autism: Measurement of the cerebellum, pons, and fourth ventricle. Biological Psychiatry, 31, 491-504.

Piven, J., Saliba, K., Bailey, J., \& Arndt, S. (1997). An MRI study of autism: The cerebellum revisited. Neurology, 49, 546-551.

Rapin, I. (1999). Autism in search of a home in the brain. Neurology, 52, 902-904.

Ritvo, E.R., Freeman, B.J., Scheibel, A.B., Duong, T., Robinson, H., Guthrie, D., \& Ritvo, A. (1986). Lower Purkinje cell counts 
in the cerebella of four autistic subjects: Initial findings of the UCLA-NSAC Autopsy Research Report. American Journal of Psychiatry, 143, 862-866.

Robb, R.A. (1995). ANALYZE: Three-dimensional biomedical imaging. New York: VCH Publishers.

Robb, R.A. (2001). ANALYZE: The biomedical imaging resource at Mayo Clinic. IEEE Transactions on Medical Imaging, 20, $854-867$.

Roche, A.F., Mukherjee, D., Guo, S.M., \& Moore, W.M. (1987). Head circumference reference data: Birth to 18 years. Pediatrics, 79, 706-712.

Rumsey, J.M., Creasey, H., Stepanek, J.S., Dorwart, R., Patronas, N., Hamburger, S.D., \& Duara, R. (1988). Hemispheric asymmetries, fourth ventricular size, and cerebellar morphology in autism. Journal of Autism and Developmental Disorders, 18, 127-137.

Saitoh, O., Courchesne, E., Egaas, B., Lincoln, A.J., \& Schreibman, L. (1995). Cross-sectional area of the posterior hippocampus in autistic patients with cerebellar and corpus callosum abnormalities. Neurology, 45, 317-324.

Schaefer, G.B., Thompson, J.N., Bodensteiner, J.B., McConnell, J.M., Kimberling, W.J., Gay, C.T., Dutton, W.D., Hutchings, D.C., \& Gray, S.B. (1996). Hypoplasia of the cerebellar vermis in neurogenetic syndromes. Annals of Neurology, 39, 382-385.

Schmahmann, J.D. \& Caplan, D. (2006). Cognition, emotion and the cerebellum. Brain, 129 (Pt 2), 290-292.

Schmahmann, J.D. \& Sherman, J.C. (1998). The cerebellar cognitive affective syndrome. Brain, 121 (Pt 4), 561-579.

Spanos, G.K., Wilde, E.A., Bigler, E.D., Cleavinger, H.B., Fearing, M.A., Levin, H.S., Li, X., \& Hunter, J.V. (2007). Cerebellar atrophy after moderate-to-severe pediatric traumatic brain injury. American Journal of Neuroradiology, 28, 537-542.

Sparks, B.F., Friedman, S.D., Shaw, D.W., Aylward, E.H., Echelard, D., Artru, A.A., Maravilla, K.R., Giedd, J.N., Munson, J., Dawson, G., \& Dager, S.R. (2002). Brain structural abnormalities in young children with autism spectrum disorder. Neurology, 59, 184-192.
Stevenson, R.E., Schroer, R.J., Skinner, C., Fender, D., \& Simensen, R.J. (1997). Autism and macrocephaly. Lancet, 349, 1744-1745.

Szatmari, P. (1999). Heterogeneity and the genetics of autism. Journal of Psychiatry \& Neuroscience, 24, 159-165.

Thach, W.T. (1996). On the specific role of the cerebellum in motor learning and cognition: Clues from PET activation and lesion studies in man. Behavioral and Brain Sciences, 19, 411-431.

Thach, W.T., Goodkin, H.P., \& Keating, J.G. (1992). The cerebellum and the adaptive coordination of movement. Annual Review of Neuroscience, 15, 403-442.

Waiter, G.D., Williams, J.H., Murray, A.D., Gilchrist, A., Perrett, D.I., \& Whiten, A. (2004). A voxel-based investigation of brain structure in male adolescents with autistic spectrum disorder. Neuroimage, 22, 619-625.

Waiter, G.D., Williams, J.H., Murray, A.D., Gilchrist, A., Perrett, D.I., \& Whiten, A. (2005). Structural white matter deficits in high-functioning individuals with autistic spectrum disorder: A voxel-based investigation. Neuroimage, 24, 455-461.

Wechsler, D. (1991). Wechsler Intelligence Scale for ChildrenThird Edition (WISC-III). San Antonio, TX: The Psychological Corporation.

Wechsler, D. (1997). Wechsler Adult Intelligence Scale-Third Edition (WAIS-III). San Antonio, TX: The Psychological Corporation.

Williams, R.S., Hauser, S.L., Purpura, D.P., DeLong, G.R., \& Swisher, C.N. (1980). Autism and mental retardation: Neuropathological studies performed in four retarded persons with autistic behavior. Archives of Neurology, 37, 749-753.

Woodhouse, W., Bailey, A., Rutter, M., Bolton, P., Baird, G., \& Le Couteur, A. (1996). Head circumference in autism and other pervasive developmental disorders. Journal of Child Psychology and Psychiatry, and Allied Disciplines, 37, 665-671. 